\title{
Eco-design of eco-labels with coarse grades
}

\author{
Emre Nadar ${ }^{\mathrm{a}, *}$, Mine Su Ertürk ${ }^{\mathrm{b}}$ \\ a Department of Industrial Engineering, Bilkent University, Ankara 06800, Turkey \\ ${ }^{\mathrm{b}}$ Graduate School of Business, Stanford University, Stanford, California 94305, United States
}

\section{A R T I C L E I N F O}

Article history:

Received 28 February 2019

Accepted 31 January 2020

Available online 3 February 2020

\section{Keywords:}

Sustainability

Eco-labels

Coarse grading

Quality and quantity competition

\begin{abstract}
A B S T R A C T
We consider a third-party eco-label certifier that aims to reduce the total environmental impact of production on non-target resources and the total consumption rate of target resources. With these objectives the certifier determines the environmental standards for coarse grades of certification. Eco-labeled production involves a fixed investment cost, a larger marginal production cost, and a restricted access to supply, while eco-labeled products command a price premium. In response to a given grading scheme, we analytically characterize the subgame perfect equilibria for a two-stage game of environmental quality investment and quantity competition in a duopolistic setting. We then conduct numerical experiments to gain insights into whether and when multi-grade eco-labels may be more useful than single-grade ecolabels by providing better environmental protection in the dual objectives of the certifier. While multiple grades of an eco-label may appear in a market with asymmetric firms, our results indicate that multiple grades can indeed be useful under additional conditions: (i) when the investment costs are asymmetric, (ii) when the investment and production costs are asymmetric, either if the firm with the cost advantage has sufficiently low production cost under mild supply restrictions or if the production costs are very different, or (iii) when the supply bases are only moderately asymmetric and sufficiently large. Our findings uncover the role the cost and supply characteristics of the market play in eco-design of eco-labels, calling into question the common practice of offering single-grade eco-labels.
\end{abstract}

(c) 2020 Elsevier Ltd. All rights reserved.

\section{Introduction}

Over the last few decades consumers have been increasingly willing to pay for environmental quality, motivating firms to incorporate green attributes into their products [12,40,59]. For environmental product differentiation, since the self-claims made by firms are often not considered credible by consumers, third-partycertified eco-labels are attracting widespread interest [5,19,29]. Eco-labels are voluntary certifications that enable consumers to easily perceive differences in environmental quality among products. Currently, there are more than 460 eco-labels in 199 countries across 25 industries (ecolabelindex.com). Among the prominent eco-labels are the Rainforest Alliance and the Fairtrade for agricultural products, the Forest Stewardship Council (FSC) for forest products, and the Marine Stewardship Council (MSC) for marine products. Eco-labeled products may command significant price premiums (for instance, premiums of up to $75 \%$ for bananas; see Potts et al. [54]). Thus, eco-labeled production has dramatically in-

\footnotetext{
This manuscript was processed by Associate Editor Joe Zhu.

* Corresponding author.

E-mail addresses: emre.nadar@bilkent.edu.tr (E. Nadar), mserturk@stanford.edu (M.S. Ertürk),
}

creased (see Atkinson and Rosenthal [3], Golden et al. [31], Howard and Allen [36], and Castka and Corbett [13], for examples).

Although eco-labels aim to truly reveal the environmental quality of products, the amount of information conveyed via ecolabels is often limited. The vast majority of eco-labels only indicate whether a firm surpasses a threshold level of quality or not (i.e., one-tier labels of the pass/fail form). A survey by Harbaugh and Rasmusen [35] shows that, of the 174 eco-labels listed at ecolabelling.org, only five eco-labels report exact grades or grades from a grading scheme with multiple levels (i.e., multi-tier labels). All of the aforementioned eco-labels are one-tier labels, while the Cradle-to-Cradle certification is one of the few eco-labels with several tiers (platinum, gold, silver, and basic). Despite the popularity of eco-labels in industry, to our knowledge no one has developed a comprehensive modeling framework that seeks to address why certifiers frequently prefer one-tier labels over the multi-tier alternatives or how effective this practice is. In this research we investigate the environmental impacts of various eco-label designs (one-tier vs. multi-tier) in different duopolistic situations (symmetric firms or asymmetric firms with respect to key operational characteristics) in order to identify whether and when multi-tier labels can help provide better environmental protection than one-tier labels. 
We consider a single third-party certifier who issues an ecolabel with two tiers - regular and premium - and specifies the environmental standards for both tiers (that we refer to as the 'ecolabel design'). Our use of a single certifier can be justified by noting the existence of the many eco-labels (especially among those with a single-sector focus) that dominate their respective marketplaces either globally or locally (see Potts et al. [54] and Bowler et al. [10], for examples). For example, Bonsucro - a single-sector initiative for cane sugar - dominates the market with a production volume of more than six times that of Fairtrade - the next most common eco-label for cane sugar. In the food and agriculture industry RSPO is very popular in Asia, whereas Organic is very common in North America. In forestry, FSC is the only certification scheme in New Zealand. One reason for such practices is that the presence of multiple eco-labels with different standards in the same market may potentially reduce the informativeness of labeling, leading to a 'non-labeling' equilibrium [34]. Our use of a two-tier (rather than a multi-tier) eco-label design is benign in our duopolistic setting because at most two certificate types can appear in the market if the eco-label has two or more tiers.

The environmental standard of an eco-label holds the certified producer responsible for improvements in (1) the environmental impact of production on non-target resources and (2) the consumption rate of target finite resources. For example, for marine products, the MSC label entails protecting by-catch species and habitats (dimension 1) and leaving sustainable fish stocks (dimension 2). See Principles 1 and 2 of the MSC label at www.msc.org. See also Agnew et al. [1], Ward [61], and Gulbrandsen [32] for detailed discussions. Improvements in (1) may translate into reducing dolphin by-catch in tuna fishery, sea turtle by-catch in shrimp fishery, sea lion by-catch in rock lobster fishery, and fur seal by-catch in hoki fishery. One can achieve such improvements by adopting special fishing gear and methods. Improvements in (2) help ensure the health and resilience of fish stocks. In general, a fish stock is considered sustainable when at least $40-60 \%$ of the total weight of fish in a particular place remains after fishing (oceanhealthindex.org). Our classification of the eco-label requirements also seems to be valid for forest products: the FSC label entails protecting rare and threatened species, biodiversity, and watercourses (dimension 1) as well as leaving representative sample areas of native ecosystems (dimension 2). See Principle 6 of the FSC label at ic.fsc.org.

We develop a two-stage duopoly model of vertical product differentiation: In stage one, each firm decides whether or not to make an investment in order to improve its environmental quality level and undergo the certification process. If a firm decides to make an investment, it raises its environmental quality level up to the environmental standard of either the regular or premium certificate. The investment required to obtain an eco-label is costly in terms of certifier's auditing and licensing fees as well as capital outlay for new advanced technologies (e.g., the adoption of special fishing gear for marine products). In stage two, each firm that has made an investment in stage one is certified accordingly. For ecolabeled production, the environmental standard requires an environmentally better production method in dimension (1) (e.g., the use of selective fishing methods) and restricted access to supply in dimension (2) (e.g., the catch limit for the fish stock). Consumers are heterogeneous in their willingness to pay for environmental quality; this can only be ascertained by certification status (no label, regular, or premium). If one firm offers products of superior quality, it does so by commanding a price premium.

For our duopolistic market, in response to any given investment-level (and thus quality) choices of the firms in stage one, we characterize the subgame equilibrium production quantities in stage two (Proposition 1). Then, in response to any given grading scheme of the eco-label, we characterize the subgame perfect equilibrium investment levels in stage one and production quantities in stage two (Proposition 2). The third-party certifier has the dual objectives of minimizing the total environmental impact of production on non-target resources (dimension 1) and the total consumption rate of target resources due to production (dimension 2). From the certifier's perspective, the eco-label can be deemed useful if there exists an eco-label design that induces at least one of the two firms to exert effort for certification and leads to improvement over the non-labeling situation in the dual objectives. Suppose that the eco-label is useful. Then the existence of a second tier can be justified if, for each particular one-tier eco-label design, there exists an eco-label design that induces the two firms to enhance their quality levels for regular and premium certificates, respectively, and leads to improvement over this particular one-tier eco-label design in the dual objectives.

We then conduct numerical experiments to gain insights into the usefulness of the eco-labels from the certifier's perspective. We calculate the Pareto optimal eco-label designs in the dual objective problem of the certifier in each of a large number of instances. The eco-label is useful if the set of Pareto optimal eco-label designs does not contain the eco-label design that sets the standards for both tiers to be the initial quality level of the two firms (i.e., the non-labeling situation). The two-tier eco-label is useful if each of the Pareto optimal eco-label designs has different standards for the two tiers that are both greater than the initial quality level. We have found that the eco-label is useful in each of our instances, while the two-tier eco-label is useful in a significant number of cases. The latter result is in contrast to the common practice of offering one-tier eco-labels.

Intuitively, the two-tier eco-label seems to be better suited to duopolistic markets with asymmetric firms. Our numerical results, however, suggest that offering a two-tier (rather than a one-tier) eco-label in such markets without closely examining the cost and supply structures of the firms may provide no additional environmental benefit in the dual objectives. Specifically, our results imply that the two-tier eco-label is useful when:

(i) The firms are asymmetric with respect to investment costs;

(ii) The firms are asymmetric with respect to investment and production costs either if the firm with the cost advantage has a sufficiently low production cost under mild supply constraints or if the firms have very different production costs; or

(iii) The firms are only moderately asymmetric with respect to supply constraints and their supply bases are sufficiently large.

We have also extended our experiments by taking the perspective of a certifier that has the objectives of not only minimizing the total environmental impact and the total consumption rate but also maximizing the total profit of the firms. This extension may be realistic for eco-labels sponsored by industry trade associations that seek to maximize the aggregate profits of the industry. One such eco-label is the Sustainable Forestry Initiative for forest products [28]. We have found that the two-tier eco-label may be useful only when the firms have very different and sufficiently large supply bases.

The rest of the paper is organized as follows: Section 2 reviews the related literature. Section 3 describes our duopolistic setting, characterizes the subgame perfect equilibria, and formulates the eco-label certifier's problem. Section 4 presents our numerical results for the certifier's problem and Section 5 concludes.

\section{Related literature}

Our work is related to the literature on strategic quality choice models. In this literature, many papers consider vertical product 
differentiation: Motta [53] compares the equilibrium quality levels under price vs. quantity competition, and those under fixed vs. variable costs of quality. Lehmann-Grube [45] reveals the economic benefits of offering high-quality products in a two-stage game of quality and price competition under fixed costs of quality. Banker et al. [4] consider vertical differentiation in oligopolistic markets and analyze the impact of competition intensity on equilibrium quality levels. Chambers et al. [15] examine the impact of variable production costs in a two-stage game of quality and price competition. Matsubayashi [51] studies quality and price competition by allowing for differentiation via factors other than quality and vertical integration among firms. Boccard and Wauthy [7] formulate a three-stage game of quality, capacity commitment, and price competition, and analyze the impact of quality costs on quality levels. Lauga and Ofek [44] develop a two-dimensional vertical differentiation model and examine the role of quality costs on product positioning. Yayla-Küllü et al. [62] consider vertical differentiation for multi-product firms in an oligopolistic market and analyze the impacts of resource constraints and competition intensity on productmix decisions. We depart from all of these papers by focusing on vertical differentiation via a credence attribute of the product - the environmental quality level - that can be discerned by consumers only through eco-labels.

Several other papers investigate the effect of imposing minimum quality standards (MQSs) to producers on social welfare: Ronnen [56] considers a duopolistic setting in which the firms compete in quality and price under fixed costs of quality and a mandatory MQS. Crampes and Hollander [18] extend the model of Ronnen [56] by allowing for variable costs of quality, and Valletti [60] considers quality and quantity competition under fixed costs of quality. Ronnen [56] and Crampes and Hollander [18] demonstrate that the existence of an MQS improves the social welfare, whereas Valletti [60] shows that this result need not extend to quantity competition. Jinji and Toshimitsu [38] generalize the analyses of Ronnen [56] and Valletti [60] by allowing the firms to be asymmetric with respect to quality costs. Kuhn [43] considers a vertically differentiated duopoly under variable costs of quality by allowing consumers to derive not only a quality-related benefit but also a quality-independent baseline benefit. Kuhn [43] shows that an MQS can enhance the welfare only if the baseline benefit is sufficiently low. Garella and Petrakis [30] analyze the impacts of an MQS on quality levels and welfare in oligopolistic markets when consumers have imperfect information about the quality of goods. In our study, unlike all these papers, the eco-label certifier makes a continuous choice for the MQS for each certificate type, and the firms have discrete choices in the levels of quality.

Our work is also related to the literature on eco-labeling schemes. In this literature, several papers highlight the potential benefits of eco-labels: In a three-stage game of investment, quality provision, and price competition, Amacher et al. [2] demonstrate that eco-labels may enable better environmental quality levels by curbing excessive investment under certain cost structures. Hamilton and Zilberman [33] find that eco-labels may reduce the sales of fraudulently-labeled products under monopolistic competition. In a three-stage game of production technology, signal, and price competition, Ibanez and Grolleau [37] show that eco-labels may improve the economic and environmental performances of duopolistic markets. Bleda and Valente [6] assert that graded eco-labels may induce firms to adopt cleaner technologies under competition. We depart from all of these papers by analyzing and comparing the implications of various eco-label designs (one-tier vs. multitier).

There are also papers that reveal the potentially adverse impacts of eco-labels: Mattoo and Singh [52] show that the elevated prices of eco-labeled products may cause increased production volumes. Dosi and Moretto [25] outline the situations in which eco- labels may raise investment for conventional technologies. Sedjo and Swallow [57] demonstrate that eco-labels may drain the profits of firms under certain conditions. Conrad [17] finds that the environmental quality choices of firms in a duopolistic setting deviate from the choices of a welfare-maximizing authority. Bottega and De Freitas [8] show that a compulsory MQS reduces the average environmental quality if a public certifier (regulator) coexists with a private certifier (for-profit or non-profit institution). Deltas et al. [23] reveal that an MQS may reduce the average environmental quality in a horizontally differentiated duopoly where the firms may differ in their 'greenness' levels. Fischer and Lyon [27] find that the environmental benefits may be smaller if a nongovernmental organization (NGO) label coexists with an industrysponsored label. Unlike these papers, we examine the impacts of various eco-label designs from the perspective of a certifier with dual environmental objectives in a vertically differentiated duopoly. Our findings suggest that eco-labels can help reduce environmental impact and that multi-tier designs can enhance this benefit under certain conditions.

In the literature on eco-labeling schemes, the closest papers to ours are those of Li and van't Veld [47] and Fischer and Lyon [28]. Li and van't Veld [47] compare the implications of single-grade single-label, multi-grade single-label, and single-grade multi-label scenarios for each of three different sponsor types: industry sponsors are indifferent among these scenarios, environmentalist sponsors may prefer multiple labels, and government sponsors may prefer multiple grades. Fischer and Lyon [28] assess the environmental impacts of grading schemes and competition of the ecolabels sponsored by NGOs and industry trade associations. When the two sponsor types compete using single-grade eco-labels, competition may provide either more or less environmental protection depending on industry structure. When they compete using multigrade eco-labels, competition always provides less environmental protection than would the NGO alone. Unlike these two papers, we take into account not only environmental quality levels but also production quantities - a legitimate concern in cases of finite resources - in our assessment of environmental impact. We also incorporate the supply constraints for production into our duopolistic setting with possibly asymmetric firms. We are thus able to provide novel insights into the eco-design of eco-labels that are not available in the above two papers.

\section{Problem formulation}

We consider a market with two competing firms ( $i=A$ and $B$ ). The firms are initially capable of offering perfectly substitutable products so that consumers are indifferent between the products that the firms offer for the same price. We denote by $\alpha_{L}$ the initial environmental quality level of both firms. Each firm may make an investment to improve the environmental quality of its product. We denote by $e_{i}$ the post-investment quality level of the product of firm $i$. Establishing credible information about the environmental quality of the product is crucial for product differentiation in the market, and third-party certifications are often effective in delivering such information $[20,55]$. In our model there is a single thirdparty eco-label certifier whose product label accurately reveals the environmental benefits of the product. Consumers respond to the credible information that is established only through the eco-label issued by this certifier.

The eco-label certifier can issue one of the following two certificates: regular or premium. It determines the minimum quality levels required to obtain regular and premium certificates, which we denote by $\alpha_{M}$ and $\alpha_{H}$, respectively. Thus $\alpha_{L} \leq \alpha_{M} \leq \alpha_{H}$. If a firm chooses to improve its environmental quality, it must obtain an eco-label in order to reap the potential benefits of the improved quality, striving for either a regular or premium certificate. 
Any investment that fails to meet the requirements of the regular certification, any investment that exceeds the requirements of the regular certification without meeting those of the premium certification, and any investment that exceeds the requirements of the premium certification have no positive return to the firm. Thus $\alpha_{L}$, $\alpha_{M}$, and $\alpha_{H}$ are the only possible quality levels that can exist in the market.

We denote by $I_{i}\left(e_{i}\right)$ the necessary level of investment for firm $i$ to achieve the quality level $e_{i} \geq \alpha_{L}$. Specifically, we assume that

$I_{i}\left(e_{i}\right)=\beta_{i}\left(e_{i}-\alpha_{L}\right)^{2}$,

where $\beta_{i} \geq 0$. For firm $i$, at any given quality level, a smaller value of the parameter $\beta_{i}$ indicates a better production capability and a lower investment cost. There are many examples of similar formulations in the related literature (see, for instance, Banker et al. [4], Economides [26], Lehmann-Grube [45], Motta [53], and Fischer and Lyon [28]). We also denote by $c_{i}\left(e_{i}\right)$ the unit production cost of firm $i$ at quality level $e_{i}$. Because the environmental standard in dimension (1) often requires more careful and selective production techniques that help reduce the environmental impact on non-target resources, it is natural to assume that $c_{i}\left(e_{i}\right)$ is non-decreasing in $e_{i}$.

We denote by $q_{i}$ the production quantity of firm $i$. The production quantity of each firm is subject to limited supply. Supply scarcity is a legitimate concern for many products that benefit from the development of eco-labels. Examples include, but are not limited to, eco-garments, seafood, edible nuts, dried fruits, and wood (CBI Ministry of Foreign Affairs [14], Connell [16], Delmas et al. [21], Jonell et al. [39], and Boukherroub et al. [9]). We denote by $Q_{i}\left(e_{i}\right)$ the maximum possible production quantity of firm $i$ with quality level $e_{i}$. Because the environmental standard in dimension (2) often imposes a restricted access to supply in order to mitigate the depletion of target resources, it is natural to assume that $Q_{i}\left(e_{i}\right)$ is non-increasing in $e_{i}$.

As a firm increases its environmental quality and becomes certified accordingly, consumers' willingness to pay for its product also increases. Consumers are heterogeneous in their willingness to pay for incremental environmental quality, which we denote by $\theta$. We assume that $\theta$ is uniformly distributed over $[0,1]$. This assumption is standard in the literature (see, for instance, Motta [53], and Kalra et al. [41]). A consumer located at $\theta$ experiences a utility of $U(e, p \mid \theta)=\theta e-p$ if she purchases a product with quality level $e$ at price $p$, and a utility of 0 if no purchase is made. A consumer does not purchase any product if her utility from the purchase of each product is negative, and she purchases the product maximizing her utility function otherwise. The competition between the two firms can be modeled as a two-stage game:

Stage One: Each firm $i \in\{A, B\}$ is fully informed by the cost structure (i.e., $I_{j}\left(e_{j}\right)$ and $\left.c_{j}\left(e_{j}\right)\right)$ and supply constraint (i.e., $\left.Q_{j}\left(e_{j}\right)\right)$ of firm $j \neq i$ as well as its own. The firms simultaneously determine the quality levels that they will offer in stage two: Each firm $i$ may make no investment (i.e., $e_{i}=\alpha_{L}$ ); may make an investment of $I_{i}\left(\alpha_{M}\right)$ to improve its quality for a regular certificate (i.e., $e_{i}=\alpha_{M}$ ); or may make an investment of $I_{i}\left(\alpha_{H}\right)$ to improve its quality for a premium certificate (i.e., $e_{i}=\alpha_{H}$ ).

Stage Two: Based on their quality level choices in stage one, the firms obtain their certificates at the beginning of stage two. The firms and consumers observe the certification status of each firm at the beginning of stage two. The firms then simultaneously determine their production quantities.

We denote by $p_{i}\left(e_{A}, e_{B}, q_{A}, q_{B}\right)$ the inverse demand function for firm $i \in\{A, B\}$ when the quality levels of firms $A$ and $B$ are $e_{A}$ and $e_{B}$, and the production quantities of firms $A$ and $B$ are $q_{A}$ and $q_{B}$, respectively. If $e_{A}=e_{B}$, the firms sell their products at the same price (in equilibrium). If $e_{A} \neq e_{B}$, the firm with superior quality has the advantage of having a higher selling price (in equilibrium). Section 3.1 formulates the inverse demand func- tion and characterizes the Nash equilibria in the second stage subgame. Section 3.2 establishes the subgame perfect equilibria. Section 3.3 describes the eco-label certifier's problem.

\subsection{The second stage}

In order to find the subgame perfect equilibria (in Section 3.2), we need to determine the Nash equilibria in the second stage subgame. To this end, we formulate the price and profit functions of both firms in stage two, characterize the best response of each firm to every possible action of its competitor in stage two, and intersect the best response functions of the two firms.

Suppose that firms $A$ and $B$ offer quality levels $e_{A}$ and $e_{B}$ with prices $p_{A}$ and $p_{B}$, respectively. Also suppose that $e_{A}>e_{B}$. For firm $B$ to have a nonzero market share, the price of firm $B$ must be lower than that of firm $A$, but the quality per dollar of firm $B$ must be higher than that of firm $A$ (i.e., $\frac{e_{B}}{p_{B}}>\frac{e_{A}}{p_{A}}$ ). This is because when the quality per dollar is lower for firm $B$ and a consumer located at $\theta$ can derive a nonnegative surplus from the product of firm $B$ (i.e., $\frac{e_{A}}{p_{A}} \geq \frac{e_{B}}{p_{B}}$ and $\theta e_{B}-p_{B} \geq 0$ ), it can be shown that this consumer always prefers to buy the product of firm $A$. The consumer located at $\theta$ buys the product of firm $A$ if and only if $\theta e_{A}-p_{A} \geq 0$ and $\theta e_{A}-p_{A} \geq \theta e_{B}-p_{B}$. Thus the set of consumers who buy the product of firm $A$ is $[\bar{\theta}, 1]$ where $\bar{\theta}=\min \{\theta: 0 \leq$ $\left.\theta \leq 1, \theta e_{A}-p_{A} \geq 0, \theta e_{A}-p_{A} \geq \theta e_{B}-p_{B}\right\}$. Since $\frac{e_{B}}{p_{B}}>\frac{e_{A}}{p_{A}}$, note that $\bar{\theta}=\min \left\{\theta: 0 \leq \theta \leq 1, \theta e_{A}-p_{A} \geq \theta e_{B}-p_{B}\right\}$. The consumer located at $\theta$ buys the product of firm $B$ if and only if $\theta e_{B}-p_{B} \geq 0$ and $\theta e_{B}-p_{B} \geq \theta e_{A}-p_{A}$. Thus the set of consumers who buy the product of firm $B$ is $[\underline{\theta}, \bar{\theta}]$ where $\underline{\theta}=\min \left\{\theta: 0 \leq \theta \leq 1, \theta e_{B}-p_{B} \geq 0\right\}$. Finally, the consumer located at $\theta \in[0, \underline{\theta}]$ does not buy any product. Hence demand for the product of firm $A$ is given by

$D_{A}\left(e_{A}, e_{B}, p_{A}, p_{B}\right)=1-\frac{p_{A}-p_{B}}{e_{A}-e_{B}}$,

and demand for the product of firm $B$ is given by

$D_{B}\left(e_{A}, e_{B}, p_{A}, p_{B}\right)=\frac{p_{A}-p_{B}}{e_{A}-e_{B}}-\frac{p_{B}}{e_{B}}=\frac{e_{B} p_{A}-e_{A} p_{B}}{e_{B}\left(e_{A}-e_{B}\right)}$.

Now suppose that $e_{A}=e_{B}$. Because the products are perfect substitutes in this case, the firms must choose the same price (i.e., $\left.p_{A}=p_{B}\right)$. Thus:

$D_{A}\left(e_{A}, e_{B}, p_{A}, p_{B}\right)+D_{B}\left(e_{A}, e_{B}, p_{A}, p_{B}\right)=1-\frac{p_{A}}{e_{A}}=1-\frac{p_{B}}{e_{B}}$.

Notice that the total demand in the market is no larger than one. (See Motta [53] and Kalra et al. [41] for similar demand formulations.)

As we want to incorporate the supply constraint into the optimization problem of each firm $i \in\{A, B\}$ by limiting the production quantity $q_{i}$, we will calculate the inverse demand function for each firm $i$, which is a mapping from the production quantities of the firms to the selling price of firm $i$. Solving the above demand equations for prices $p_{A}$ and $p_{B}$, and substituting $q_{A}$ and $q_{B}$ for $D_{A}(\cdot)$ and $D_{B}(\cdot)$, respectively, we obtain the following inverse demand functions for firms $A$ and $B$ when $e_{A} \geq e_{B}$ :

$p_{A}\left(e_{A}, e_{B}, q_{A}, q_{B}\right)=e_{A}-e_{A} q_{A}-e_{B} q_{B}$

and

$p_{B}\left(e_{A}, e_{B}, q_{A}, q_{B}\right)=e_{B}-e_{B} q_{A}-e_{B} q_{B}$.

The inverse demand functions when $e_{A} \leq e_{B}$ can be easily obtained by interchanging the subscripts $A$ and $B$ in the above equations. (See Dixit [24], Singh and Vives [58], and Banker et al. [4] for similar price formulations.) In the remainder of the paper, for brevity, we restrict our analysis to settings in which (i) the production quantities in equilibrium are guaranteed to be nonnegative and (ii) 
the total production quantity in equilibrium is guaranteed to be no larger than one. With the above price functions, we are now ready to formulate the profit of each firm $i$ in stage two as a function of the environmental quality levels and production quantities of both firms:

$\Pi_{i 2}\left(e_{A}, e_{B}, q_{A}, q_{B}\right)=p_{i}\left(e_{A}, e_{B}, q_{A}, q_{B}\right) q_{i}-c_{i}\left(e_{i}\right) q_{i}$

subject to $q_{i} \leq Q_{i}\left(e_{i}\right)$. By characterizing the best response functions of the two firms and intersecting these functions, we are able to find the Nash equilibria in stage two:

Proposition 1. Suppose that firms $A$ and $B$ offer quality levels $e_{A}$ and $e_{B}$, respectively, in stage two. Then the Nash equilibrium quantities when $e_{A} \geq e_{B}$ can be specified as follows:

$$
\begin{aligned}
& \left(q_{A}^{*}\left(e_{A}, e_{B}\right), q_{B}^{*}\left(e_{A}, e_{B}\right)\right) \\
& \quad=\left\{\begin{array}{l}
\left(\frac{2 e_{A}-e_{B}-2 c_{A}\left(e_{A}\right)+c_{B}\left(e_{B}\right)}{4 e_{A}-e_{B}}, \frac{e_{A}+c_{A}\left(e_{A}\right)-2\left(e_{A} / e_{B}\right) c_{B}\left(e_{B}\right)}{4 e_{A}-e_{B}}\right) \\
\text { if } \frac{2 e_{A}-e_{B}-2 c_{A}\left(e_{A}\right)+c_{B}\left(e_{B}\right)}{4 e_{A}-e_{B}} \leq Q_{A}\left(e_{A}\right) \text { and } \frac{e_{A}+c_{A}\left(e_{A}\right)-2\left(e_{A} / e_{B}\right) c_{B}\left(e_{B}\right)}{4 e_{A}-e_{B}} \leq Q_{B}\left(e_{B}\right), \\
\left(Q_{A}\left(e_{A}\right), \frac{e_{B}-e_{B} Q_{A}\left(e_{A}\right)-c_{B}\left(e_{B}\right)}{2 e_{B}}\right) \\
\text { if } \frac{2 e_{A}-e_{B}-2 c_{A}\left(e_{A}\right)+c_{B}\left(e_{B}\right)}{4 e_{A}-e_{B}}>Q_{A}\left(e_{A}\right) \text { and } \frac{e_{B}-e_{B} Q_{A}\left(e_{A}\right)-c_{B}\left(e_{B}\right)}{2 e_{B}} \leq Q_{B}\left(e_{B}\right), \\
\left.\frac{e_{A}-e_{B} Q_{B}\left(e_{B}\right)-c_{A}\left(e_{A}\right)}{2 e_{A}}, Q_{B}\left(e_{B}\right)\right) \\
\text { if } \frac{e_{A}-e_{B} Q_{B}\left(e_{B}\right)-c_{A}\left(e_{A}\right)}{2 e_{A}} \leq Q_{A}\left(e_{A}\right) \text { and } \frac{e_{A}+c_{A}\left(e_{A}\right)-2\left(e_{A} / e_{B}\right) c_{B}\left(e_{B}\right)}{4 e_{A}-e_{B}}>Q_{B}\left(e_{B}\right), \\
\left(Q_{A}\left(e_{A}\right), Q_{B}\left(e_{B}\right)\right) \\
\text { if } \frac{e_{A}-e_{B} Q_{B}\left(e_{B}\right)-c_{A}\left(e_{A}\right)}{2 e_{A}}>Q_{A}\left(e_{A}\right) \text { and } \frac{e_{B}-e_{B} Q_{A}\left(e_{A}\right)-c_{B}\left(e_{B}\right)}{2 e_{B}}>Q_{B}\left(e_{B}\right) .
\end{array}\right.
\end{aligned}
$$

Proof of Proposition 1. We first characterize the best response of firm $A$ to action $q_{B}$ of firm $B$ when $e_{A} \geq e_{B}: B R_{A}\left(e_{A}, e_{B}, q_{B}\right)$ denotes the action that maximizes $\Pi_{A 2}\left(e_{A}, e_{B}, q_{A}, q_{B}\right)$ subject to $q_{A} \leq Q_{A}\left(e_{A}\right)$. Note that $\frac{\partial \Pi_{A 2}\left(e_{A}, e_{B}, q_{A}, q_{B}\right)}{\partial q_{A}}=e_{A}-2 e_{A} q_{A}-e_{B} q_{B}-c_{A}\left(e_{A}\right)$ and $\frac{\partial^{2} \Pi_{A 2}\left(e_{A}, e_{B}, q_{A}, q_{B}\right)}{\partial q_{A}^{2}}=-2 e_{A}<0$. Thus, from the first order condition, the unconstrained maximizer of $\Pi_{A 2}\left(e_{A}, e_{B}, q_{A}, q_{B}\right)$ is $\frac{e_{A}-e_{B} q_{B}-c_{A}\left(e_{A}\right)}{2 e_{A}}$. But if $Q_{A}\left(e_{A}\right)<\frac{e_{A}-e_{B} q_{B}-c_{A}\left(e_{A}\right)}{2 e_{A}}$, it is optimal to produce the quantity $Q_{A}\left(e_{A}\right)$. Hence,

$B R_{A}\left(e_{A}, e_{B}, q_{B}\right)=\min \left\{\frac{e_{A}-e_{B} q_{B}-c_{A}\left(e_{A}\right)}{2 e_{A}}, Q_{A}\left(e_{A}\right)\right\}$.

We also characterize the best response of firm $B$ to action $q_{A}$ of firm $A$ when $e_{A} \geq e_{B}: B R_{B}\left(e_{A}, e_{B}, q_{A}\right)$ denotes the action that maximizes $\Pi_{B 2}\left(e_{A}, e_{B}, q_{A}, q_{B}\right)$ subject to $q_{B} \leq Q_{B}\left(e_{B}\right)$. Note that $\frac{\partial \Pi_{B 2}\left(e_{A}, e_{B}, q_{A}, q_{B}\right)}{\partial q_{B}}=e_{B}-e_{B} q_{A}-2 e_{B} q_{B}-c_{B}\left(e_{B}\right)$ and $\frac{\partial^{2} \Pi_{B 2}\left(e_{A}, e_{B}, q_{A}, q_{B}\right)}{\partial q_{B}^{2}}=$ $-2 e_{B}<0$. Thus the unconstrained maximizer of $\Pi_{B 2}\left(e_{A}, e_{B}, q_{A}, q_{B}\right)$ is $\frac{e_{B}-e_{B} q_{A}-c_{B}\left(e_{B}\right)}{2 e_{B}}$. But if $Q_{B}\left(e_{B}\right)<\frac{e_{B}-e_{B} q_{A}-c_{B}\left(e_{B}\right)}{2 e_{B}}$, it is optimal to produce the quantity $Q_{B}\left(e_{B}\right)$. Hence,

$B R_{B}\left(e_{A}, e_{B}, q_{B}\right)=\min \left\{\frac{e_{B}-e_{B} q_{A}-c_{B}\left(e_{B}\right)}{2 e_{B}}, Q_{B}\left(e_{B}\right)\right\}$.

Intersecting the best response functions, we obtain the four different Nash equilibrium solutions in Proposition 1 and the conditions ensuring each of these Nash equilibrium solutions.

\subsection{The first stage}

We denote by $\Pi_{i 2}^{*}\left(e_{A}, e_{B}\right)$ the second stage equilibrium profit of firm $i$ as a function of the environmental quality levels of both firms. One can easily calculate $\Pi_{i 2}^{*}\left(e_{A}, e_{B}\right)$ by plugging the second stage equilibrium quantities of the firms associated with the quality levels $e_{A}$ and $e_{B}$ (available from Proposition 1) into the second stage profit function of firm $i$. Recall our definitions of $\alpha_{L}, \alpha_{M}$, and $\alpha_{H}$. We label the pair $\left(\alpha_{M}, \alpha_{H}\right)$ as the two-tier eco-label design specified by the certifier. Notice that our equilibrium results (below) for two-tier designs can be extended to one-tier designs: If $\alpha_{M}=\alpha_{H}$, the regular and premium certificates are identical. If $\alpha_{M}=\alpha_{L}$, the regular certificate reduces to the non-labeling situation. These two special cases correspond to one-tier eco-labels in which a certificate is either awarded or not awarded. We next formulate the total profit of each firm $i \in\{A, B\}$ in stages one and two as a function of the quality levels $e_{A}, e_{B} \in\left\{\alpha_{L}, \alpha_{M}, \alpha_{H}\right\}$ :

$\Pi_{i 1}\left(e_{A}, e_{B}\right)=\Pi_{i 2}^{*}\left(e_{A}, e_{B}\right)-I_{i}\left(e_{i}\right)$.

We now establish the subgame perfect equilibria for our two-stage game:

Proposition 2. Suppose that (a) $\Pi_{A 2}^{*}\left(e_{A}, e_{B}\right)-I_{A}\left(e_{A}\right) \geq$ $\max _{e \in\left\{\alpha_{L}, \alpha_{M}, \alpha_{H}\right\}, e \neq e_{A}}\left\{\Pi_{A 2}^{*}\left(e, e_{B}\right)-I_{A}(e)\right\}$ and (b) $\Pi_{B 2}^{*}\left(e_{A}, e_{B}\right)-$ $I_{B}\left(e_{B}\right) \geq \max _{e \in\left\{\alpha_{L}, \alpha_{M}, \alpha_{H}\right\}, e \neq e_{B}}\left\{\Pi_{B 2}^{*}\left(e_{A}, e\right)-I_{B}(e)\right\}$. Then the equilibrium quality levels of firms $A$ and $B$ are $e_{A}$ and $e_{B}$, respectively, and their equilibrium quantities are as described byProposition 1.

Proof of Proposition 2. Given that firm $B$ chooses quality level $e_{B}$ in stage one, point (a) implies that the best response of firm $A$ in stage one is to choose quality level $e_{A}$. Given that firm $A$ chooses quality level $e_{A}$ in stage one, point (b) implies that the best response of firm $B$ in stage one is to choose quality level $e_{B}$. Hence, the equilibrium quality levels of firms $A$ and $B$ are $e_{A}$ and $e_{B}$, respectively. The equilibrium quantities in stage two are the same as those described by Proposition 1 under the condition set that is satisfied.

\subsection{The certifier's problem}

We denote by $e_{i}^{*}\left(\alpha_{M}, \alpha_{H}\right)$ the equilibrium quality level of firm $i$ (available from Proposition 2) in response to the eco-label design $\left(\alpha_{M}, \alpha_{H}\right)$. We assume that the environmental impact per unit of production is linearly and inversely proportional to the environmental quality of the product, and the environmental impact is zero at the highest possible quality level. (See Fischer and Lyon [28] for a similar environmental impact calculation.) The eco-label certifier has the dual objectives of minimizing the total production quantity in equilibrium, which can be written as

$$
\begin{aligned}
Q\left(\alpha_{M}, \alpha_{H}\right)= & q_{A}^{*}\left(e_{A}^{*}\left(\alpha_{M}, \alpha_{H}\right), e_{B}^{*}\left(\alpha_{M}, \alpha_{H}\right)\right) \\
& +q_{B}^{*}\left(e_{A}^{*}\left(\alpha_{M}, \alpha_{H}\right), e_{B}^{*}\left(\alpha_{M}, \alpha_{H}\right)\right),
\end{aligned}
$$

and the total environmental impact in equilibrium, which can be written as

$$
\begin{aligned}
E\left(\alpha_{M}, \alpha_{H}\right)= & \left(\bar{\alpha}-e_{A}^{*}\left(\alpha_{M}, \alpha_{H}\right)\right) q_{A}^{*}\left(e_{A}^{*}\left(\alpha_{M}, \alpha_{H}\right), e_{B}^{*}\left(\alpha_{M}, \alpha_{H}\right)\right) \\
& +\left(\bar{\alpha}-e_{B}^{*}\left(\alpha_{M}, \alpha_{H}\right)\right) q_{B}^{*}\left(e_{A}^{*}\left(\alpha_{M}, \alpha_{H}\right), e_{B}^{*}\left(\alpha_{M}, \alpha_{H}\right)\right)
\end{aligned}
$$

where $\bar{\alpha}$ is the highest possible quality level. An eco-label design $\left(\alpha_{M}, \alpha_{H}\right)$ is Pareto optimal if and only if there is no other feasible eco-label design $\left(\widetilde{\alpha}_{M}, \tilde{\alpha}_{H}\right)$ such that $Q\left(\widetilde{\alpha}_{M}, \tilde{\alpha}_{H}\right) \leq Q\left(\alpha_{M}, \alpha_{H}\right)$ and $E\left(\widetilde{\alpha}_{M}, \widetilde{\alpha}_{H}\right)<E\left(\alpha_{M}, \alpha_{H}\right)$, or such that $Q\left(\widetilde{\alpha}_{M}, \widetilde{\alpha}_{H}\right)<Q\left(\alpha_{M}, \alpha_{H}\right)$ and $E\left(\widetilde{\alpha}_{M}, \widetilde{\alpha}_{H}\right) \leq E\left(\alpha_{M}, \alpha_{H}\right)$. We denote by $\mathcal{P}$ the set of Pareto optimal eco-label designs.

Definition 1. From the certifier's perspective, the eco-label is deemed useful if and only if $\left(\alpha_{L}, \alpha_{L}\right) \notin \mathcal{P}$, whereas the two-tier eco-label is deemed useful if and only if $\alpha_{M} \neq \alpha_{L}, \alpha_{H} \neq \alpha_{L}$, and $\alpha_{M} \neq \alpha_{H}$, $\forall\left(\alpha_{M}, \alpha_{H}\right) \in \mathcal{P}$.

If the eco-label is useful according to Definition 1, the certifier is able to specify environmental standards for its eco-label that not only induce at least one of the two firms to get certified but also provide better environmental protection than the non-labeling situation in the dual objectives. If the two-tier eco-label is useful, the certifier is able to specify environmental standards that not only induce the two firms to get regular and premium certificates, respectively, but also provide better environmental protection than any specific one-tier eco-label design in the dual objectives. 
(a) Equilibrium quality level of firm $A$.

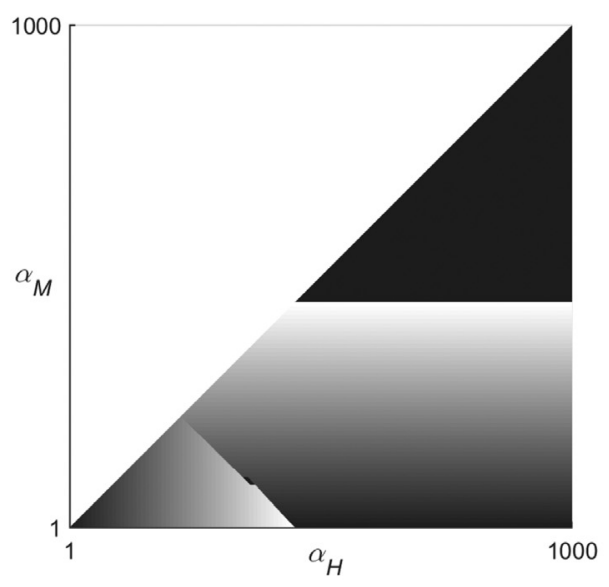

(c) Equilibrium quantity of firm $A$.

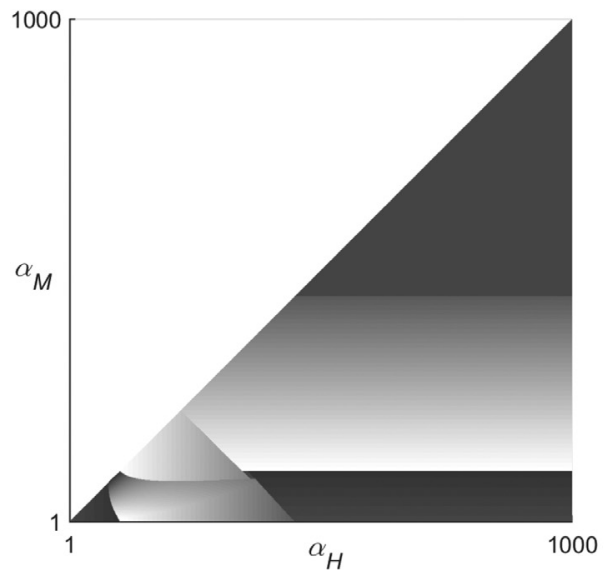

(b) Equilibrium quality level of firm $B$.

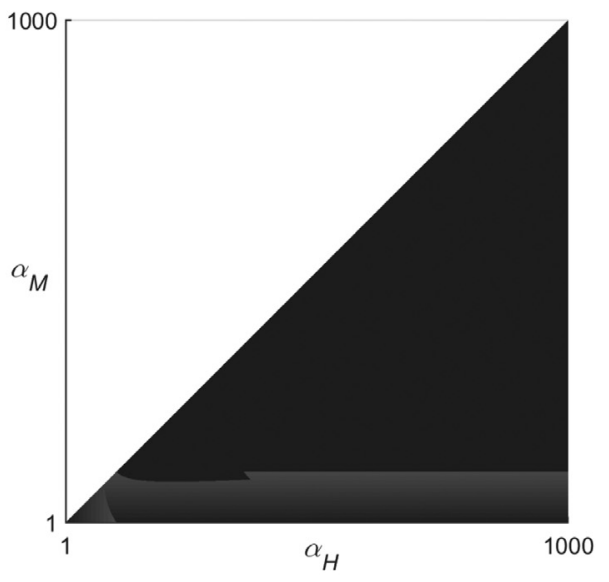

(d) Equilibrium quantity of firm $B$.

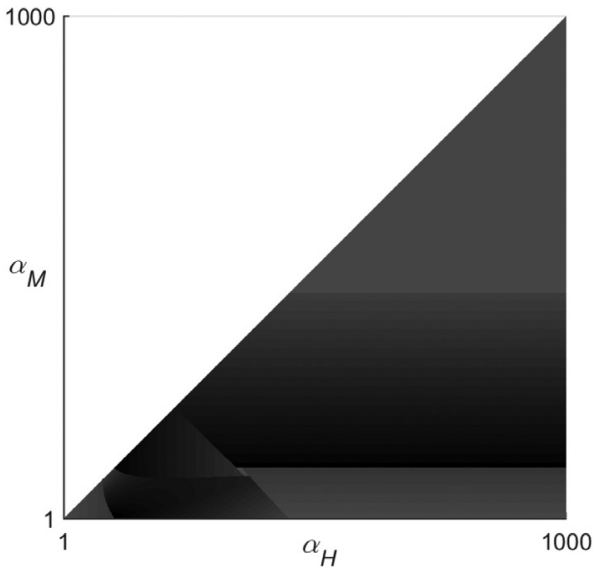

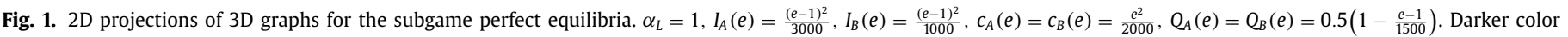
indicates lower value. The equilibrium solution with the highest total profit appears in case of multiple equilibria.

As we could not analytically characterize the set of Pareto optimal eco-label designs, we calculate this set with the complete enumeration method in our numerical experiments in Section 4. We demonstrate below our steps in calculating the Pareto optimal set in a numerical example, providing explanations of our key observations. We consider a duopolistic setting where $\alpha_{L}=1, \bar{\alpha}=1000$, $e_{A}, e_{B} \in\{1, \ldots, 1000\}, I_{A}(e)=\frac{(e-1)^{2}}{3000}, I_{B}(e)=\frac{(e-1)^{2}}{1000}, c_{A}(e)=c_{B}(e)=$ $\frac{e^{2}}{2000}$, and $Q_{A}(e)=Q_{B}(e)=0.5\left(1-\frac{e-1}{1500}\right)$. Notice that the firms are asymmetric with respect to only investment costs: firm $A$ can achieve the same quality level as firm $B$ with a lower investment cost. Figs. 1-2 exhibit the subgame perfect equilibria conditional on the eco-label design $\left(\alpha_{M}, \alpha_{H}\right)$ in our example.

The firms are not certified if $\alpha_{M}$ is large (the top right triangular-like regions in Fig. 1a and $b$ ). This is because very high standards involve high investment/production costs and severe supply restrictions. Firm $A$ gets certified if $\alpha_{M}$ is low: it prefers the premium certificate if $\alpha_{H}$ is small (the bottom left triangularlike region in Fig. 1a), and the regular certificate otherwise. But firm $B$ gets certified if $\alpha_{M}$ is too low: it prefers the premium certificate if $\alpha_{H}$ is too small (the bottom left triangular-like region in Fig. 1b), and the regular certificate otherwise. Hence, because firm $A$ is more advantageous than firm $B$ in terms of investment cost, the quality level of firm $A$ is no less than that of firm $B$ for each specific eco-label design. The firms offer the same quantity if no firm is certified (the top right triangular regions in Fig. 1c and d), or if both firms get the premium certificate (the bottom left triangular-like regions in Fig. 1c and d), or if both firms get the regular certificate (the bottom right trapezoid-like regions in Fig. 1c and d). When the firms have the same certificate, the quantity of each firm slightly grows as the standard for the certificate drops: the firms focus more on improving their quantities by offering lower prices for their products with lower standards. The quantity of firm $A$ is always no less than that of firm $B$ if firm $A$ has superior quality (the regions in Fig. $1 \mathrm{c}$ and $d$ other than those depicted above): The firms refrain from high-standard labels that require large investment costs. Thus only low-standard labels can arise in equilibrium. A low-standard label induces firm $A$ to offer a small price premium. Since the low-standard label only slightly increases the production cost, firm $A$ can afford a price premium that is small enough to raise its demand. The increased demand can be met thanks to the mild supply restrictions of the low-standard label.

The Pareto optimal set in our example is $\mathcal{P}=\{(1,101)$, $(101,101),(85,370)\} \cup\{(101,356),(101,357), \ldots,(101,1000)\}$. For $\left(\alpha_{M}, \alpha_{H}\right) \in \mathcal{P} \backslash\{(85,370)\}$, both firms choose the quality level 101, which is the highest possible level that can arise in equilibrium when the firms have the same certificate. Fig. 2 indicates that the total production quantity is lowest when $\left(\alpha_{M}, \alpha_{H}\right) \in \mathcal{P} \backslash$ $\{(85,370)\}$. For $\left(\alpha_{M}, \alpha_{H}\right)=(85,370)$, firms $A$ and $B$ choose the 
(a) Total production quantity in equilibrium

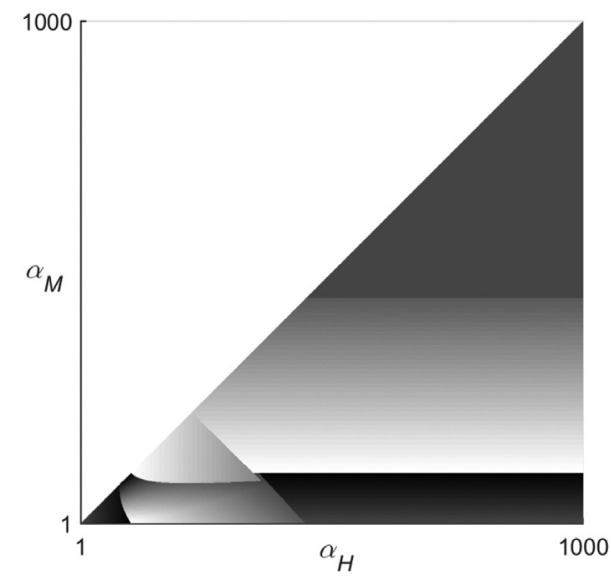

(c) Total profit in equilibrium.

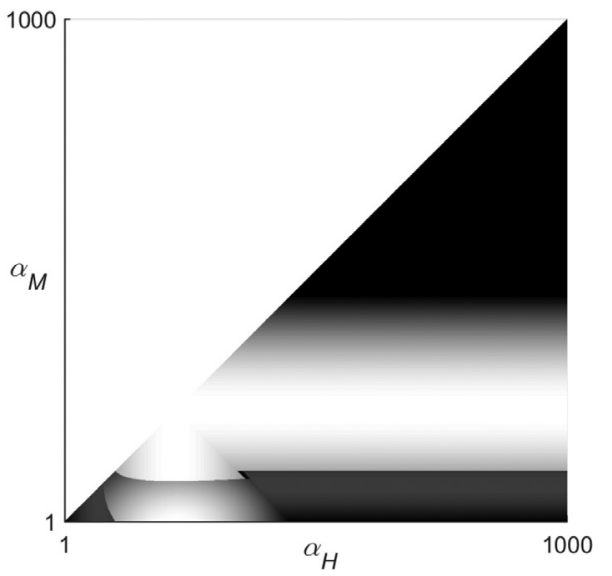

(b) Total environmental impact in equilibrium.

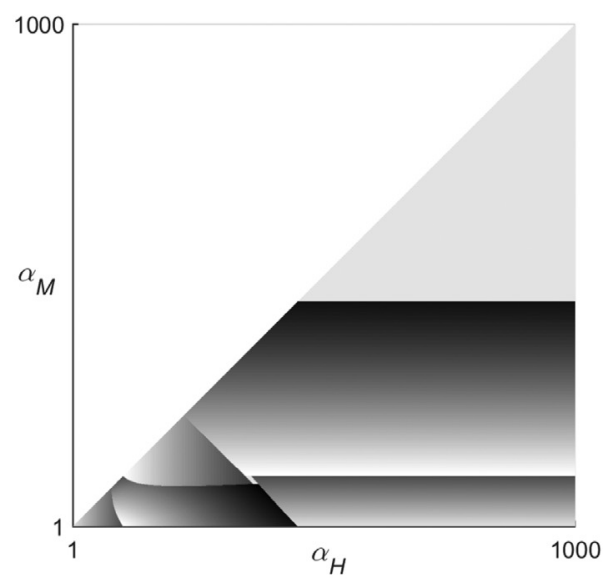

(d) Pareto optimal designs.

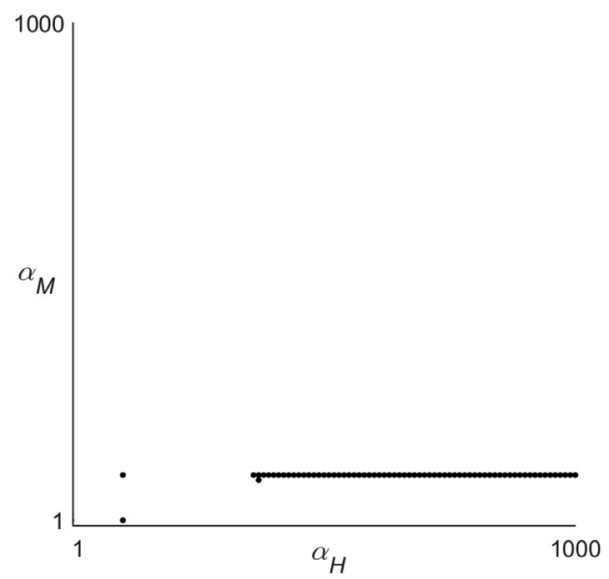

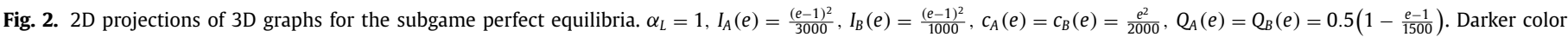

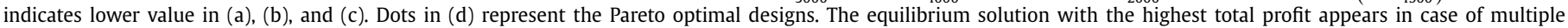
equilibria.

quality levels 370 and 85 , respectively, the sum of which is the highest possible sum of the levels that can arise in equilibrium. Fig. 2 indicates that the total environmental impact is lowest when $\left(\alpha_{M}, \alpha_{H}\right)=(85,370)$. The eco-label is useful in this example since the Pareto optimal set does not contain (1,1): at least one Pareto optimal design is better than the non-labeling situation (i.e., $\alpha_{M}=$ $\alpha_{H}=1$ ) in the dual objectives. But the second tier is not useful since the Pareto optimal set contains $(1,101)$ and $(101,101)$ : no twotier design is better than the one-tier design $\alpha_{M}=\alpha_{H}=101$ in the dual objectives.

\section{Numerical experiments}

In this section, we conduct numerical experiments to investigate the environmental impacts of various eco-label designs (identified by quality requirements $\alpha_{M}$ and $\alpha_{H}$ ) in a wide variety of duopolistic situations: when the firms are asymmetric with respect to investment costs (Section 4.1), unit production costs (Section 4.2), and supply constraints (Section 4.3). We also examine the impact of incorporating an economic perspective into the eco-label design problem (Section 4.4).

In our experiments we take $\alpha_{L}=1 \leq \alpha_{M} \leq \alpha_{H} \leq \bar{\alpha}=1000$. Thus the investment cost function of each firm $i$ is given by $I_{i}\left(e_{i}\right)=$ $\beta_{i}\left(e_{i}-1\right)^{2}$. We assume that the unit production cost of each firm $i$ is quadratically increasing in its quality level $e_{i}: c_{i}\left(e_{i}\right)=\gamma_{i} e_{i}^{2}$ where the coefficient $\gamma_{i}$ allows the firms to differ in their cost efficiencies. Our quadratic cost function reflects the fact that each additional increment of environmental protection is likely to be more difficult, and thus more expensive, to achieve [48]. We also assume that the maximum possible production quantity of each firm $i$ is linearly and inversely proportional to its quality level $e_{i}: Q_{i}\left(e_{i}\right)=$ $\rho_{i}\left(1-\frac{e_{i}-1}{1000}\right)$ where the coefficient $\rho_{i}$ is the production capacity of firm $i$ in the non-labeling situation. (The firms may have different productions capacities in the non-labeling situation. For example, for marine products, the fishing capacity of a firm is often limited by its vessel or fleet size. Small-scale fisheries have small vessels with a limited area of operation. See Carvalho et al. [11].) Note that the production quantity of each firm $i$ is virtually zero at the highest possible quality level 1000 .

We consider three different sets of instances:

(i) A total of 125 instances in which $\beta_{A}=1 / 3000$, $\beta_{B} \in\{1 / 1000,1 / 1500,1 / 2000,1 / 2500,1 / 3000\}$, $\gamma_{A}=1 / 4000, \quad \gamma_{B} \in\{1 / 2000,1 / 2500,1 / 3000,1 / 3500$, $1 / 4000\}, \rho_{A}=0.50$, and $\rho_{B} \in\{0.10,0.20,0.30,0.40,0.50\}$;

(ii) $\mathrm{A}$ total of 125 instances in which $\beta_{A}=1 / 3000$, $\beta_{B} \in\{1 / 1000,1 / 1500,1 / 2000,1 / 2500,1 / 3000\}$, $\gamma_{A}=1 / 3000, \quad \gamma_{B} \in\{1 / 2000,1 / 2250,1 / 2500,1 / 2750$, $1 / 3000\}, \rho_{A}=0.50$, and $\rho_{B} \in\{0.10,0.20,0.30,0.40,0.50\}$; and 
Table 1

Pareto optimal eco-label designs.

\begin{tabular}{lllll}
\hline$\beta_{B}$ & One-tier designs $\left(\alpha_{H}\right)$ & Two-tier designs $\left(\alpha_{M}, \alpha_{H}\right)$ & Is two-tier useful? \\
\cline { 3 - 5 } & & Lowest environmental impact & Lowest production quantity \\
\hline $1 / 1000$ & $\emptyset$ & $(106,404)$ & $(2,482)$ & Yes \\
$1 / 1500$ & $\emptyset$ & $(155,369)$ & $(2,482)$ & Yes \\
$1 / 2000$ & $\emptyset$ & $(192,345)$ & $(2,482)$ & Yes \\
$1 / 2500$ & 245 & $(229,326)$ & $(245,322)$ & No \\
$1 / 3000$ & 287 & $(287,289)$ & $(2,287)$ & No \\
\hline
\end{tabular}

$\beta_{A}=1 / 3000, \gamma_{A}=\gamma_{B}=1 / 4000, \rho_{A}=\rho_{B}=0.50$.

Table 2

Pareto optimal eco-label designs.

\begin{tabular}{lllll}
\hline$\gamma_{B}$ & One-tier designs $\left(\alpha_{H}\right)$ & \multicolumn{2}{l}{ Two-tier designs $\left(\alpha_{M}, \alpha_{H}\right)$} & \multirow{2}{*}{ Is two-tier useful? } \\
\cline { 3 - 5 } & & Lowest environmental impact & Lowest production quantity & Yes \\
\hline $1 / 2000$ & $\emptyset$ & $(135,381)$ & $(133,383)$ & Yes \\
$1 / 2500$ & $\emptyset$ & $(142,377)$ & $(142,377)$ & Yes \\
$1 / 3000$ & $\emptyset$ & $(147,374)$ & $(2,482)$ & Yes \\
$1 / 3500$ & $\emptyset$ & $(151,371)$ & $(2,482)$ & Yes \\
$1 / 4000$ & $\emptyset$ & $(155,369)$ & $(2,482)$ & \\
\hline
\end{tabular}

$\beta_{A}=1 / 3000, \beta_{B}=1 / 1500, \gamma_{A}=1 / 4000, \rho_{A}=\rho_{B}=0.50$.

Table 3

Pareto optimal eco-label designs.

\begin{tabular}{lllll}
\hline$\gamma_{B}$ & One-tier designs $\left(\alpha_{H}\right)$ & \multicolumn{2}{l}{ Two-tier designs $\left(\alpha_{M}, \alpha_{H}\right)$} & Is two-tier useful? \\
\cline { 3 - 4 } & & Lowest environmental impact & Lowest production quantity & Yes \\
\hline $1 / 2000$ & $\emptyset$ & $(138,357)$ & $(138,357)$ & No \\
$1 / 2250$ & 142 & $(142,355)$ & $(142,356)$ & No \\
$1 / 2500$ & 145 & $(144,354)$ & $(2,145)$ & No \\
$1 / 2750$ & 148 & $(146,353)$ & $(2,148)$ & No \\
$1 / 3000$ & 151 & $(147,352)$ & $(151,350)$ & \\
\hline
\end{tabular}

$\beta_{A}=1 / 3000, \beta_{B}=1 / 1500, \gamma_{A}=1 / 3000, \rho_{A}=\rho_{B}=0.50$.

Table 4

Pareto optimal eco-label designs.

\begin{tabular}{lllll}
\hline$\gamma_{B}$ & One-tier designs $\left(\alpha_{H}\right)$ & Two-tier designs $\left(\alpha_{M}, \alpha_{H}\right)$ & \multirow{2}{*}{ Is two-tier useful? } \\
\cline { 3 - 5 } & & Lowest environmental impact & Lowest production quantity & Yes \\
\hline $1 / 2000$ & $\emptyset$ & $(170,355)$ & $(170,355)$ & Yes \\
$1 / 2500$ & $\emptyset$ & $(181,349)$ & $(180,350)$ & Yes \\
$1 / 3000$ & $\emptyset$ & $(185,348)$ & $(2,482)$ & Yes \\
$1 / 3500$ & $\emptyset$ & $(191,345)$ & $(2,482)$ & Yes \\
$1 / 4000$ & $\emptyset$ & $(192,345)$ & & \\
\hline
\end{tabular}

$\beta_{A}=1 / 3000, \beta_{B}=1 / 2000, \gamma_{A}=1 / 4000, \rho_{A}=\rho_{B}=0.50$.

(iii) A total of 125 instances in which $\beta_{A}=1 / 3000$, $\beta_{B} \in\{1 / 1000,1 / 1500,1 / 2000,1 / 2500,1 / 3000\}$, $\gamma_{A}=1 / 4000, \quad \gamma_{B} \in\{1 / 2000,1 / 2500,1 / 3000,1 / 3500$, $1 / 4000\}, \rho_{A}=0.30$, and $\rho_{B} \in\{0.10,0.15,0.20,0.25,0.30\}$.

Notice that firm $A$ is more advantageous than firm $B$ in all asymmetric cases, firm $A$ has a lower unit production cost on test bed (i) than on test bed (ii), and firm $A$ has a larger supply base on test bed (i) than on test bed (iii). Our choice of values for $\beta_{A}$ and $\beta_{B}$ allows the firms' certificate type choices to vary depending on the eco-label design, enabling us to observe the active role the certifier plays in shaping the market in all instances. Our choice of values for $\gamma_{A}$ and $\gamma_{B}$ guarantees strictly positive production quantities for both firms for all eco-label designs in all instances. Finally, the supply scarcity is not a concern in the non-labeling situation for our instances with $\rho_{A}=\rho_{B}=0.50$ (since the total demand cannot be larger than one).

We calculate the Pareto optimal eco-label designs from the certifier's perspective in each instance. We have found that there is no instance for which the non-labeling situation (i.e., $\alpha_{M}=\alpha_{H}=1$ ) is in the set of Pareto optimal designs. This implies that the eco-label is useful in each instance. Tables 1-7 exhibit the one-tier design, the two-tier design with the lowest environmental impact, and the two-tier design with the lowest production quantity, which are Pareto optimal, for each of the selected 35 instances (all included on test beds i-iii). Tables 8-10 exhibit whether the two-tier ecolabel is useful or not for each instance on test beds (i)-(iii), respectively.

\subsection{Firms with asymmetric investment costs}

We observe from Table 1 that when the investment required to improve quality is much larger for firm $B$ than firm $A$ (i.e., when $\beta_{B} \geq 1 / 2000$ ), there is no one-tier design in the Pareto optimal set: A high-standard one-tier design discourages firm $B$ from certification due to its high investment cost, thus leading to a large amount of non-labeled production. A low-standard one-tier design may encourage firm $B$ to get certified, but the environmental quality of all eco-labeled products is low in this case and the resulting low premium offered by both firms can only slightly reduce the production quantity. However, a two-tier design that sets a distinctly high standard for the premium certificate is likely to encourage firm $A$ 
Table 5

Pareto optimal eco-label designs.

\begin{tabular}{lllll}
\hline$\gamma_{B}$ & One-tier designs $\left(\alpha_{H}\right)$ & \multicolumn{2}{l}{ Two-tier designs $\left(\alpha_{M}, \alpha_{H}\right)$} & \multirow{2}{*}{ Is two-tier useful? } \\
\cline { 3 - 5 } & & Lowest environmental impact & Lowest production quantity \\
\hline $1 / 2000$ & $\emptyset$ & $(201,221)$ & $(200,222)$ & Yes \\
$1 / 2500$ & $\emptyset$ & $(210,213)$ & $(210,213)$ & Yes \\
$1 / 3000$ & 215 & $(215,216)$ & $(215,216)$ & No \\
$1 / 3500$ & 220 & $(220,221)$ & $(220,221)$ & No \\
$1 / 4000$ & 223 & $(223,224)$ & $(223,224)$ & No \\
\hline$\beta_{A}=1 / 3000$ & $\beta_{B}=1 / 2000, \gamma_{A}=1 / 4000, \rho_{A}=\rho_{B}=0.30$ &
\end{tabular}

$\beta_{A}=1 / 3000, \beta_{B}=1 / 2000, \gamma_{A}=1 / 4000, \rho_{A}=\rho_{B}=0.30$.

Table 6

Pareto optimal eco-label designs.

\begin{tabular}{lllll}
\hline$\rho_{B}$ & One-tier designs $\left(\alpha_{H}\right)$ & \multicolumn{2}{l}{ Two-tier designs $\left(\alpha_{M}, \alpha_{H}\right)$} & Is two-tier useful? \\
\cline { 3 - 4 } & & Lowest environmental impact & Lowest production quantity & No \\
\hline 0.10 & 482 & $(482,483)$ & $(482,483)$ & Yes \\
0.20 & $\emptyset$ & $(2,482)$ & $(2,482)$ & Yes \\
0.30 & $\emptyset$ & $(166,360)$ & $(2,482)$ & No \\
0.40 & 278 & $(278,279)$ & $(278,279)$ & No \\
\hline
\end{tabular}

$\beta_{A}=\beta_{B}=1 / 3000, \gamma_{A}=\gamma_{B}=1 / 4000, \rho_{A}=0.50$.

Table 7

Pareto optimal eco-label designs.

\begin{tabular}{lllll}
\hline \multirow{2}{*}{$\rho_{B}$} & One-tier designs $\left(\alpha_{H}\right)$ & \multicolumn{2}{l}{ Two-tier designs $\left(\alpha_{M}, \alpha_{H}\right)$} & Is two-tier useful? \\
\cline { 3 - 4 } & & Lowest environmental impact & Lowest production quantity & No \\
\hline 0.10 & 393 & $(393,394)$ & $(393,394)$ & No \\
0.15 & 393 & $(5,390)$ & $(393,394)$ & No \\
0.20 & 253 & $(253,254)$ & $(253,254)$ & No \\
0.25 & 287 & $(287,288)$ & $(287,288)$ & No \\
0.30 & 315 & $(315,316)$ & $(315,316)$ & \\
\hline
\end{tabular}

$\beta_{A}=\beta_{B}=1 / 3000, \gamma_{A}=\gamma_{B}=1 / 4000, \rho_{A}=0.30$.

Table 8

Is two-tier eco-label useful?

\begin{tabular}{lllllll}
\hline & $\beta_{B}$ & $\gamma_{B}=\frac{1}{2000}$ & $\gamma_{B}=\frac{1}{2500}$ & $\gamma_{B}=\frac{1}{3000}$ & $\gamma_{B}=\frac{1}{3500}$ & $\gamma_{B}=\frac{1}{4000}$ \\
\hline$\rho_{B}=0.10$ & $1 / 1000$ & No & No & No & No & No \\
& $1 / 1500$ & No & No & No & No & No \\
& $1 / 2000$ & No & No & No & No & No \\
& $1 / 2500$ & No & No & No & No & No \\
& $1 / 3000$ & No & No & No & No & No \\
$\rho_{B}=0.20$ & $1 / 1000$ & Yes & Yes & Yes & Yes & Yes \\
& $1 / 1500$ & Yes & Yes & Yes & Yes & Yes \\
& $1 / 2000$ & Yes & Yes & Yes & Yes & Yes \\
& $1 / 2500$ & Yes & Yes & Yes & Yes & Yes \\
& $1 / 3000$ & Yes & Yes & Yes & Yes & Yes \\
$\rho_{B}=0.30$ & $1 / 1000$ & Yes & Yes & Yes & Yes & Yes \\
& $1 / 1500$ & Yes & Yes & Yes & Yes & Yes \\
& $1 / 2000$ & Yes & Yes & Yes & Yes & Yes \\
& $1 / 2500$ & Yes & Yes & Yes & Yes & Yes \\
& $1 / 3000$ & Yes & Yes & Yes & Yes & Yes \\
& $1 / 1000$ & Yes & Yes & Yes & Yes & Yes \\
& $1 / 1500$ & Yes & Yes & Yes & Yes & Yes \\
& $1 / 2000$ & Yes & Yes & Yes & Yes & Yes \\
& $1 / 2500$ & No & No & No & No & No \\
& $1 / 3000$ & No & No & No & No & No \\
& $1 / 1000$ & Yes & Yes & Yes & Yes & Yes \\
& $1 / 1500$ & Yes & Yes & Yes & Yes & Yes \\
& $1 / 2000$ & Yes & Yes & Yes & Yes & Yes \\
& $1 / 2500$ & No & No & No & No & No \\
& $1 / 3000$ & No & No & No & No & No \\
\hline$\rho_{B}=0.50$ & & & & &
\end{tabular}

$\beta_{A}=1 / 3000, \gamma_{A}=1 / 4000, \rho_{A}=0.50$.

to obtain the premium certificate and firm $B$ to obtain the regular certificate, resulting in an improvement in the dual objectives. We also note from Table 1 that when the firms have similar investment costs (i.e., when $\beta_{B} \leq 1 / 2500$ ), the Pareto optimal sets contain one-tier designs: the firms tend to obtain the same certifi- cate in this case, negating the need for a second tier for further improvement in the dual objectives. Based on these observations, we conclude that the existence of a second tier can be deemed useful when the firms are asymmetric with respect to investment costs. 
Table 9

Is two-tier eco-label useful?

\begin{tabular}{|c|c|c|c|c|c|c|}
\hline & $\beta_{B}$ & $\gamma_{B}=\frac{1}{2000}$ & $\gamma_{B}=\frac{1}{2250}$ & $\gamma_{B}=\frac{1}{2500}$ & $\gamma_{B}=\frac{1}{2750}$ & $\gamma_{B}=\frac{1}{3000}$ \\
\hline \multirow[t]{5}{*}{$\rho_{B}=0.10$} & $1 / 1000$ & No & No & No & No & No \\
\hline & $1 / 1500$ & No & No & No & No & No \\
\hline & $1 / 2000$ & No & No & No & No & No \\
\hline & $1 / 2500$ & No & No & No & No & No \\
\hline & $1 / 3000$ & No & No & No & No & No \\
\hline \multirow[t]{5}{*}{$\rho_{B}=0.20$} & $1 / 1000$ & No & No & No & No & No \\
\hline & $1 / 1500$ & No & No & No & No & No \\
\hline & $1 / 2000$ & No & No & No & No & No \\
\hline & $1 / 2500$ & No & No & No & No & No \\
\hline & $1 / 3000$ & No & No & No & No & No \\
\hline \multirow[t]{5}{*}{$\rho_{B}=0.30$} & $1 / 1000$ & Yes & Yes & Yes & Yes & Yes \\
\hline & $1 / 1500$ & Yes & Yes & Yes & Yes & Yes \\
\hline & $1 / 2000$ & Yes & Yes & Yes & Yes & Yes \\
\hline & $1 / 2500$ & Yes & Yes & Yes & Yes & Yes \\
\hline & $1 / 3000$ & Yes & Yes & Yes & Yes & Yes \\
\hline \multirow[t]{5}{*}{$\rho_{B}=0.40$} & $1 / 1000$ & Yes & Yes & Yes & Yes & Yes \\
\hline & $1 / 1500$ & Yes & No & No & No & No \\
\hline & $1 / 2000$ & No & No & No & No & No \\
\hline & $1 / 2500$ & No & No & No & No & No \\
\hline & $1 / 3000$ & No & No & No & No & No \\
\hline \multirow[t]{5}{*}{$\rho_{B}=0.50$} & $1 / 1000$ & Yes & Yes & Yes & Yes & Yes \\
\hline & $1 / 1500$ & Yes & No & No & No & No \\
\hline & $1 / 2000$ & No & No & No & No & No \\
\hline & $1 / 2500$ & No & No & No & No & No \\
\hline & $1 / 3000$ & No & No & No & No & No \\
\hline
\end{tabular}

$\beta_{A}=1 / 3000, \gamma_{A}=1 / 3000, \rho_{A}=0.50$.

Table 10

Is two-tier eco-label useful?

\begin{tabular}{lllllll}
\hline & $\beta_{B}$ & $\gamma_{B}=\frac{1}{2000}$ & $\gamma_{B}=\frac{1}{2500}$ & $\gamma_{B}=\frac{1}{3000}$ & $\gamma_{B}=\frac{1}{3500}$ & $\gamma_{B}=\frac{1}{4000}$ \\
\hline$\rho_{B}=0.10$ & $1 / 1000$ & No & No & No & No & No \\
& $1 / 1500$ & No & No & No & No & No \\
& $1 / 2000$ & No & No & No & No & No \\
& $1 / 2500$ & No & No & No & No & No \\
& $1 / 3000$ & No & No & No & No & No \\
$\rho_{B}=0.15$ & $1 / 1000$ & No & No & No & No & No \\
& $1 / 1500$ & No & No & No & No & No \\
& $1 / 2000$ & No & No & No & No & No \\
& $1 / 2500$ & No & No & No & No & No \\
& $1 / 3000$ & No & No & No & No & No \\
$\rho_{B}=0.20$ & $1 / 1000$ & No & No & No & No & No \\
& $1 / 1500$ & No & No & No & No & No \\
& $1 / 2000$ & No & No & No & No & No \\
& $1 / 2500$ & No & No & No & No & No \\
& $1 / 3000$ & No & No & No & No & No \\
& $1 / 1000$ & Yes & Yes & Yes & Yes & Yes \\
& $1 / 1500$ & Yes & Yes & Yes & Yes & Yes \\
& $1 / 2000$ & Yes & Yes & Yes & Yes & Yes \\
& $1 / 2500$ & No & No & No & No & No \\
& $1 / 3000$ & No & No & No & No & No \\
& $1 / 1000$ & Yes & Yes & Yes & Yes & Yes \\
& $1 / 1500$ & Yes & Yes & Yes & Yes & Yes \\
& $1 / 2000$ & Yes & Yes & No & No & No \\
& $1 / 2500$ & No & No & No & No & No \\
& $1 / 3000$ & No & No & No & No & No \\
\hline$\rho_{B}=0.30$ & & & & &
\end{tabular}

$\beta_{A}=1 / 3000, \gamma_{A}=1 / 4000, \rho_{A}=0.30$.

\subsection{Firms with asymmetric production costs}

We will now focus on two different scenarios in Table 1 in which the firms are asymmetric with respect to investment costs and the two-tier eco-label is useful. First, we consider the scenario with $\beta_{B}=1 / 1500$ in Table 1 . We observe from Table 2 that the two-tier eco-label remains useful if the firms also become asymmetric with respect to production costs when $\beta_{B}=1 / 1500$ : When firm $B$ pays a larger production cost than firm $A$ at the same quality level, a high-standard one-tier design hinders firm $B$ from certification due to its high production cost (in addition to its high investment cost), again leading to a large amount of non-labeled production. One-tier designs with standards that are too low may encourage certification, but again the environmental quality of all products is too low in this case and the resulting low premium only slightly reduces the production quantity. A two-tier design having a distinctly high standard for the premium certificate may thus result in further improvement in the dual objectives.

However, we may obtain different results if the production cost of firm $A$ is increased: For the instances in Table 2, we assume that $\gamma_{A}=1 / 3000 \leq \gamma_{B}$ rather than $\gamma_{A}=1 / 4000 \leq \gamma_{B}$. Table 3 reveals that the Pareto optimal sets may contain one-tier designs when 
the firms are asymmetric with respect to investment and production costs: a low-standard one-tier design can be useful when $\gamma_{B} \leq 1 / 2250$ in that it encourages both firms to get certified and reduces the production quantity significantly. This is because firm $A$ should offer a high premium due to its high production cost and firm $B$ should offer an even higher premium due to its cost disadvantage. An exception to this observation is when $\gamma_{B}=1 / 2000$ in Table 3: The standards of a one-tier eco-label that can induce firm $B$ to get certified are too low in this case. The environmental quality of all eco-labeled products is too low under such standards. In addition, because the increase in the production cost of firm $A$ due to certification is only marginal under such standards, the premium becomes so small that the production quantity can only be slightly reduced.

We now consider the scenario with $\beta_{B}=1 / 2000$ in Table 1 . We observe from Table 4 that the two-tier eco-label again remains useful if the firms also become asymmetric with respect to production costs when $\beta_{B}=1 / 2000$. But we may obtain different results if the production capacities of both firms are reduced: For the instances in Table 4 , we assume that $\rho_{A}=\rho_{B}=0.30$ rather than $\rho_{A}=\rho_{B}=0.50$. Table 5 reveals that the Pareto optimal sets contain one-tier designs when $\gamma_{B} \leq 1 / 3000$ : a low-standard one-tier eco-label can encourage both firms to get certified, but can also reduce the production quantity substantially under scarce resources. However, the Pareto optimal sets contain no one-tier design when $\gamma_{B} \geq 1 / 2500$ : the standards of a one-tier eco-label that can induce firm $B$ to get certified are too low in these cases.

Based on all of these observations, we conclude that the existence of a second tier can be deemed useful when the firms are asymmetric with respect to investment and production costs (i) if the advantageous firm has a sufficiently low production cost and the firms have mild supply constraints or (ii) if the unit production costs are highly asymmetric.

\subsection{Firms with asymmetric supply constraints}

We observe from Table 6 that when firm $B$ has a moderately limited supply (i.e., when $\rho_{B} \in\{0.20,0.30\}$ ), there is no one-tier design in the Pareto optimal set: A high-standard one-tier design discourages firm $B$ from certification because it would greatly suffer from the highly restricted access to supply imposed by the ecolabel. A low-standard one-tier design may encourage firm $B$ to get certified, but with a slight improvement in environmental quality and a slight decrease in production quantity. It is thus useful to offer a two-tier design having a distinctly high standard for the premium certificate. However, when firm $B$ has a severely limited supply (i.e., when $\rho_{B}=0.10$ ), the Pareto optimal set contains a onetier design: Firm $B$ has only a little impact on the total environmental impact and total production quantity due to its severely limited production capacity. Because firm $A$ dominates the market and prefers to get certified, focusing on firm $A$ and proposing a high-standard one-tier design can be sufficient without introducing a second tier. We also note from Table 6 that when the firms have similar supply constraints (i.e., when $\rho_{B} \in\{0.40,0.50\}$ ), the Pareto optimal sets again contain one-tier designs: because the firms tend to obtain the same certificate in this case, proposing a one-tier design can again be sufficient without introducing a second tier. In addition to these observations, for the instances in Table 6, we now assume that $\rho_{A}=0.30 \geq \rho_{B}$ rather than $\rho_{A}=$ $0.50 \geq \rho_{B}$. Table 7 reveals that a two-tier design fails to be useful in this case even when the firms are asymmetric with respect to supply constraints: a high-standard premium certificate becomes less attractive for firm $A$, while a low-standard one-tier label can raise the premium and lower the production quantity substantially, under scarce resources. Based on all of these observations, we conclude that the existence of a second tier can be deemed useful when the firms have moderately different and sufficiently large supply bases.

\subsection{The objective of total profit maximization}

Finally, we consider a certifier with the objectives of not only minimizing the total environmental impact and the total production quantity but also maximizing the total profit of the two firms. We calculate the Pareto optimal eco-label designs from this certifier's perspective in each of our instances. We have found that there is no instance for which the non-labeling situation (i.e., $\alpha_{M}=$ $\alpha_{H}=1$ ) is in the Pareto optimal set. This implies that the eco-label is again useful in each instance. Also, there is no one-tier design in the Pareto optimal set in each of the 25 instances in which $\rho_{A}=0.50, \rho_{B}=0.20, \beta_{A}=1 / 3000, \beta_{B} \in\{1 / 1000,1 / 1500,1 / 2000$, $1 / 2500,1 / 3000\}, \gamma_{A}=1 / 4000$, and $\gamma_{B} \in\{1 / 2000,1 / 2500,1 / 3000$, 1/3500, 1/4000\}: the existence of a second tier may be useful only when the firms have very different and sufficiently large supply bases. This is because a two-tier design with a distinctly high standard for the premium certificate not only induces both certificate types to be adopted in this case but also limits the production quantity of firm $A$ substantially. The resulting low quantity of firm $A$, combined with the severe supply constraint of firm $B$, leads to high prices in equilibrium so that the eco-label can improve the total profit of the two firms.

\section{Concluding remarks}

We have studied the problem of a third-party eco-label certifier, which determines the minimum quality standards for coarse grades of the eco-label to improve the environmental performance of the target marketplace. Our study provides additional support for the usefulness of eco-labels (one-tier or two-tier) from the certifier's perspective in a wide variety of duopolistic situations (symmetric firms or asymmetric firms with respect to operational characteristics). But our results do not seem to confirm the common practice of offering one-tier eco-labels: two-tier eco-labels can be more useful than one-tier eco-labels in duopolistic settings (i) when the firms are asymmetric with respect to investment costs; (ii) when they are asymmetric with respect to investment and production costs, if the advantageous firm has a sufficiently low production cost under mild supply restrictions or if their production costs are very different; or (iii) when they are only moderately asymmetric with respect to mild supply restrictions. These results highlight the importance of taking into account the cost and supply structures of the firms in the eco-design of eco-labels.

Future research may extend our analysis to oligopolistic markets in which the certifier issues multiple certificate types. We intuitively expect the cost and supply structures to have similar effects in duopolistic and oligopolistic markets. We also conjecture that multi-tier eco-labels may become more useful as competition intensity increases with the number of firms in the market. Another direction for future work is to investigate the impact of different information structures on eco-label designs. For instance, one firm might have limited information about the cost and supply structures and/or the quality choice of the other firm. See Mason [49] and Ibanez and Grolleau [37] for incomplete information models. Future research may also incorporate uncertainty into the certification process. For instance, when a firm exerts effort for certification, the eco-label may or may not be granted, depending on the quality level that is ultimately realized. See Kirchhoff [42], Mason and Sterbenz [50], and Mason [49] for models with imperfect certification mechanisms. Lastly, future work may allow for the addition of multiple certifiers who issue competing ecolabels. Such an extension should take into account the consumer 
confusion caused by eco-label proliferation; see Harbaugh et al. [34], Leire and Thidell [46], and Delmas and Grant [22].

\section{CRediT authorship contribution statement}

Emre Nadar: Conceptualization, Methodology, Software, Validation, Formal analysis, Investigation, Writing - review \& editing, Visualization, Supervision. Mine Su Ertürk: Conceptualization, Methodology, Software, Validation, Formal analysis, Investigation, Writing - original draft.

\section{Acknowledgment}

The authors are grateful to the associate editor and five anonymous referees for their constructive comments and suggestions. They also thank Bilkent University for financial support.

\section{References}

[1] Agnew D, Grieve C, Orr P, Parkes G, Barker N. Environmental benefits resulting from certification against MSCs Principles and Criteria for Sustainable Fishing: 2006. MRAG UK Ltd. and MSC, London

[2] Amacher GS, Koskela E, Ollikainen M. Environmental quality competition and eco-labeling. J Environ Econ Manage 2004;47(2):284-306.

[3] Atkinson L, Rosenthal S. Signaling the green sell: the influence of eco-labe source, argument specificity, and product involvement on consumer trust. J Advert 2014;43(1):33-45.

[4] Banker RD, Khosla I, Sinha KK. Quality and competition. Manage Sci 1998;44(9):1179-92.

[5] Belz F-M, Peattie K. Sustainability marketing: a global perspective. Wiley Chichester; 2009

[6] Bleda M, Valente M. Graded eco-labels: a demand-oriented approach to reduce pollution. Technol Forecast Soc Change 2009;76(4):512-24.

[7] Boccard N, Wauthy XY. Equilibrium vertical differentiation in a bertrand mode with capacity precommitment. Int J Ind Organiz 2010;28(3):288-97.

[8] Bottega L, De Freitas J. Public, private and nonprofit regulation for environmental quality. J Econ Manage Strat 2009;18(1):105-23.

[9] Boukherroub T, LeBel L, Ruiz A. A framework for sustainable forest resource allocation: a Canadian case study. Omega (Westport) 2017:66:224-35.

[10] Bowler K, Castka P, Balzarova M. Understanding firms' approaches to voluntary certification: evidence from multiple case studies in FSC certification. J Bus Ethics 2017;145(2):441-56.

[11] Carvalho N, Edwards-Jones G, Isidro E. Defining scale in fisheries: small versus large-scale fishing operations in the Azores. Fish Res 2011;109(2-3):360-9.

[12] Cason TN, Gangadharan L. Environmental labeling and incomplete consumer information in laboratory markets. J Environ Econ Manage 2002:43(1):113-34

[13] Castka P, Corbett CJ. Governance of eco-labels: expert opinion and media coverage. J Bus Ethics 2016;135(2):309-26.

[14] CBI Ministry of Foreign Affairs. Edible nuts and dried fruit in Europe. 2016 Https://www.cbi.eu/market-information/processed-fruit-vegetables-ediblenuts/competition-edible-nuts-dried-fruits.

[15] Chambers C, Kouvelis P, Semple J. Quality-based competition, profitability, and variable costs. Manage Sci 2006:52(12):1884-95.

[16] Connell KYH. Internal and external barriers to eco-conscious apparel acquisition. Int J Consum Stud 2010;34(3):279-86.

[17] Conrad K. Price competition and product differentiation when consumers care for the environment. Environ Resour Econ 2005;31(1):1-19.

[18] Crampes C, Hollander A. Duopoly and quality standards. Eur Econ Rev 1995;39(1):71-82.

[19] Dando N, Swift T. Transparency and assurance minding the credibility gap. J Bus Ethics 2003;44(2):195-200.

[20] Darnall N, Ji H, Vázquez-Brust DA. Third-party certification, sponsorship, and consumers' ecolabel use. J Bus Ethics 2018;150(4):953-69.

[21] Delmas MA, Nairn-Birch N, Balzarova M. Choosing the right eco-label for your product. MIT Sloan Manage Rev 2013;54(4):10-12.

[22] Delmas MA, Grant LE. Eco-labeling strategies and price-premium: the wine industry puzzle. Bus Soc 2014:53(1):6-44.

[23] Deltas G, Harrington DR, Khanna M. Oligopolies with (somewhat) environmentally conscious consumers: market equilibrium and regulatory intervention. J Econ Manage Strat 2013;22(3):640-67.

[24] Dixit A. A model of duopoly suggesting a theory of entry barriers. Bell J Econ 1979;10(1):20-32.

[25] Dosi C, Moretto M. Is ecolabelling a reliable environmental policy measure? Environ Resour Econ 2001;18(1):113-27.

[26] Economides N. Quality choice and vertical integration. Int J Ind Organiz 1999;17(6):903-14.
[27] Fischer C, Lyon TP. Competing environmental labels. J Econ Manage Strat 2014;23(3):692-716

[28] Fischer C, Lyon TP. A theory of multi-tier ecolabel competition. 2016; Working paper.

[29] Galarraga Gallastegui I. The use of eco-labels: a review of the literature. Eur Environ 2002:12(6):316-31.

[30] Garella PG, Petrakis E. Minimum quality standards and consumers information. Econ Theory 2008;36(2):283-302.

[31] Golden JS, Vermeer D, Clemen B, Michalko A, Nguyen D, Noyes C, Akella A Bunting J. An overview of ecolabels and sustainability certifications in the global marketplace. Nicholas Institute for Environmental Policy Solutions, Duke University; 2010. p. 1-99.

[32] Gulbrandsen LH. The emergence and effectiveness of the marine stewardship council. Mar Policy 2009;33(4):654-60.

[33] Hamilton SF, Zilberman D. Green markets, eco-certification, and equilibrium fraud. J Environ Econ Manage 2006;52(3):627-44.

[34] Harbaugh R, Maxwell JW, Roussillon B. Label confusion: the Groucho effect of uncertain standards. Manage Sci 2011;57(9):1512-27.

[35] Harbaugh R, Rasmusen E. Coarse grades: informing the public by withholding information. Am Econ J 2018;10(1):210-35.

[36] Howard PH, Allen P. Beyond organic and fair trade? an analysis of ecolabel preferences in the united states. Rural Sociol 2010;75(2):244-69.

[37] Ibanez L, Grolleau G. Can ecolabeling schemes preserve the environment? Environ Resour Econ 2008;40(2):233-49.

[38] Jinji N, Toshimitsu T. Minimum quality standards under asymmetric duopoly with endogenous quality ordering: a note. J Regul Econ 2004;26(2):189-99.

[39] Jonell M, Phillips M, Rönnbäck P, Troell M. Eco-certification of farmed seafood: will it make a difference? Ambio 2013:42(6):659-74.

[40] Kaiser MJ, Edwards-Jones G. The role of ecolabeling in fisheries management and conservation. Conserv Biol 2006;20(2):392-8.

[41] Kalra A, Rajiv S, Srinivasan K. Response to competitive entry: a rationale for delayed defensive reaction. Market Sci 1998;17(4):380-405

[42] Kirchhoff S. Green business and blue angels. Environ Resour Econ 2000;15(4):403-20.

[43] Kuhn M. Minimum quality standards and market dominance in vertically differentiated duopoly. Int J Ind Organiz 2007;25(2):275-90.

[44] Lauga DO, Ofek E. Product positioning in a two-dimensional vertical differentiation model: the role of quality costs. Market Sci 2011;30(5):903-23.

[45] Lehmann-Grube U. Strategic choice of quality when quality is costly: the persistence of the high-quality advantage. Rand J Econ 1997;28(2):372-84.

[46] Leire C, Thidell A. Product-related environmental information to guide consumer purchases-a review and analysis of research on perceptions, understanding and use among nordic consumers. J Clean Prod 2005;13(10):1061-70.

[47] Li Y, van't Veld K. Green, greener, greenest: eco-label gradation and competi tion. J Environ Econ Manage 2015;72:164-76.

[48] Liu ZL, Anderson TD, Cruz JM. Consumer environmental awareness and competition in two-stage supply chains. Eur J Oper Res 2012;218(3):602-13

[49] Mason CF. An economic model of ecolabeling. Environ Model Assess 2006;11(2):131-43.

[50] Mason CF, Sterbenz FP. Imperfect product testing and market size. Int Econ Rev (Philadelphia) 1994;35(1):61-86

[51] Matsubayashi N. Price and quality competition: the effect of differentiation and vertical integration. Eur J Oper Res 2007;180(2):907-21.

[52] Mattoo A, Singh HV. Eco-labelling: policy considerations. Kyklos 1994;47(1):53-65.

[53] Motta M. Endogenous quality choice: price vs. quantity competition. J Ind Econ 1993;41(2):113-31

[54] Potts J, Lynch M, Wilkings A, Huppé G, Cunningham M, Voora V. The state of sustainability initiatives review 2014: Standards and the green economy; 2014. International Institute for Sustainable Development (IISD) and the International Institute for Environment and Development (IIED), London

[55] Reinhardt FL. Down to earth: applying business principles to environmental management. Harvard Business Press; 2000.

[56] Ronnen U. Minimum quality standards, fixed costs, and competition. Rand Econ 1991;22(4):490-504.

[57] Sedjo RA, Swallow SK. Voluntary eco-labeling and the price premium. Land Econ 2002;78(2):272-84

[58] Singh N, Vives X. Price and quantity competition in a differentiated duopoly Rand J Econ 1984;15(4):546-54.

[59] Thompson DW, Anderson RC, Hansen EN, Kahle LR. Green segmentation and environmental certification: insights from forest products. Bus Strat Environ 2010;19(5):319-34.

[60] Valletti TM. Minimum quality standards under cournot competition. J Regul Econ 2000;18(3):235-45.

[61] Ward TJ. Barriers to biodiversity conservation in marine fishery certification. Fish Fisheries 2008;9(2):169-77.

[62] Yayla-Küllü HM, Parlaktürk AK, Swaminathan JM. Multi-product quality competition: impact of resource constraints. Prod Oper Manage 2013;22(3):603-14. 